\title{
PELATIHAN TATA GRAHA RUMAH WISATA BAGI PENGELOLA HOMESTAY DI NAGARI HARAU
}

\author{
Lise Asnur ${ }^{1}$,Dadi Satria ${ }^{2}$,Khairi Budayawan ${ }^{3}$ \\ ${ }^{1,}$ Program Studi Manajemen Perhotelan FPP UNP \\ ${ }^{2}$ Program Studi Pendidikan Bahasa Indonesia FBS UNP \\ ${ }^{3}$ Program Studi Pendidikan Teknik Elektronika FT UNP \\ Jalan Dr.Hamka,Air Tawar.Kota Padang \\ 1e-mail:lise.asnur@fpp.unp.ac.id
}

\begin{abstract}
Abstrak
Program Kemitraan Masyarakat ini bertujuan memberikan kontribusi kepada Pengelola Homestay di Kenagarian Harau, Kecamatan Harau melaksanakan tata graha meliputi perancangan desain visual interior dan eksterior, pemeliharaan fasilitas, pembersihan dan penataan ruangan kamar dan kamar mandi rumah wisata sehingga membuat tamu nyaman dan aman, serta bermanfaat bagi wisatawan. Metode pengabdian yang digunakan adalah demonstrasi.Kegiatan pengabdian mulai dari tahap persiapan yakni observasi dan sosialisasi, sedangkan untuk pelaksanaan mulai dari penyajian materi, praktik, refleksi dan evaluasi.Hasil kegiatan pengabdian adalah: (1) Pelaksanaan kegiatan terselenggara dengan baik, berjalan lancar, dan peserta memiliki antusias yang luar biasa sepanjang kegiatan berlangsung; (2) Peserta sangat aktif dalam mempraktikan operasional tata graha dan mengikuti dengan motivasi yang tinggi, dan (3) Peserta pelatihan mendapatkan keterampilan baru dalam operasional tata graha, sehingga dapat diimplementasikan di homestay yang mereka kelola sehingga dapat meningkatkan kualitas homestay.
\end{abstract}

KataKunci:Tata Graha, Interior, Eksterior, Rumah Wisata

Abstract

This Community Partnership Program contributes to the Homestay Manager in Kenagarian Harau, Harau District to carry out spatial and interior design and design, provision of facilities, installation and arrangement of tourist rooms and bathrooms that make travel comfortable and safe, and beneficial for tourists. The service method used is demonstration. Community service activities start from the preparation of the socialization preparation, while the implementation starts from the presentation of material, practice, reflection and evaluation. The results of the Community Service Activities are: (1) The implementation of the activities is carried out well, runs smoothly, and participants have tremendous enthusiasm throughout the activity; (2) Participants are very active in practicing housing operational governance and participating with high motivation, and (3) Training participants acquire new skills in housing operational management, which can be implemented in homestays where they want to improve homestay quality.

Keywords: Housekeeping, Interior, Exterior, Tourist House

\section{PENDAHULUAN}

Lembah Harau terletak di Nagari Harau, Kecamatan Harau, Kabupaten Lima Puluh Kota, Propinsi Sumatera Barat. Kecamatan Harau merupakan salah satu kecamatan di Kabupaten Lima Puluh Kota, letaknya diapit oleh empat 
kecamatan, dengan batas wilayah sebagai berikut: sebelah utara Kecamatan Pangkalan Koto Baru sebelah selatan Kecamatan Payakumbuh, sebelah barat Kecamatan Mungka, sebelah timur Provinsi Riau. Dengan Luas wilayah Kecamatan Harau sebesar 416,80 Km2. Kecamatan Harau memiliki 3 objek wisata yaitu objek wisata Lembah Harau, Kapalo Banda yang terletak di nagari Harau dan Jalan Layang (Fly Over) Kelok Sembilan. Lembah Harau ini sudah banyak diketahui oleh masyarakat umumnya dan banyak dikunjungi oleh wisatawan mancanegara.Objek wisata Lembah harau mempunyai daya tarik wisata berupa perbukitan dengan dinding batu yang terjal, air terjun, sungai yang mengalir dari air terjun, Objek wisata alam Lembah Harau memiliki 3 resort yaitu Resort Aka Barayun, Resort Sarasah Bunta dan Resort Rimbo Piobang. Resor Aka Barayun merupakan salah satu tempat rekreasi anakdan remaja dengan berbagai jenis daya tarik dan jenis permainan anak.

Berdasarkan hal tersebut, Kecamatan Harau memiliki potensi wisata yang luar biasa. Sebuah daerah tujuan wisata setidaknya memiliki tiga elemen utama yakni destinasi wisata, karakteristik wisata, dan inti informasi. Ketiga elemen tersebut merupakan dasar tujuan wisata yang dapat mempengaruhi wisatawan rela melakukan perjalanan yang jauh ataupun mengeluarkan dana yang besar untuk menikmati destinasi wisata yang tersedia. Dengan demikian, unsur pokok ini harus dikelola dan dikembangkan melalui perencanaan, pelaksanaan pembangunan, dan pengembangan berbagai aspek vital destinasi wisata yang telah dimiliki, salah satunya adalah rumah wisata (homestay).

Prasarana wisata merupakan sumberdaya alami dan buatan manusia yang sejatinya merupakan unsur mutlak yang harus tersedia pada destinasi wisata. (Suwantoro, 1997)menyebutkan bahwa kesiapan objek wisata perlu dibangun dengan menyesuaikan antara lokasi dengan kondisi objek wisata tersebut. Hal ini dimaksudkan untuk meningkatkan akseptabilitas sebuah objek wisata yang bermuara pada peningkatan kunjungan wisatawan. Pembangunan sarana dan prasarana di destinasi wisata harus disesuaikan dengan kebutuhan wisatawan baik secara kuantitaif maupun kualitatif. Secara kualitatif maksudnya di sini merujuk pada jumlah dan kuantitas sarana wisata yang tersedia. Sementara secara 
kuantitatif berkenaan dengan mutu pelayanan yang diberikan kepada wisatawan sehingga dapat dilihat dari tingkat kepuasan wisatawan yang mendapatkan pelayanan.

Salah satu bentuk akomodasi yang dapatditawarkan kepada wisatawan adalah rumahwisata (homestay). Homestays memampukan wisatawanuntuk memiliki tempat berteduh dengansuasana yang menyerupai rumah selama mereka menghabiskan waktu di tempattujuan tertentu. Hal ini memungkinkan wisatawan untuk semakin mengenal tempatsetempat atau bahkan meningkatkan keterampilan penguasaan atas bahasasetempat. Sehingga melalui cara ini, para wisatawan mendapatkan pilihan selaintinggal di hotel, guesthouse atau backpackers. Memiliki sebuah homestay dapatmemberikan pengalaman yang memuaskan baik kepada pemilik homestay maupunkepada wisatawan. Cara bisnis ini dapat membantu pemilik homestay menghasilkanuang tambahan, bertemu dengan orang-orang yang menarik, dan mereka jugadapat berbagi tradisi dan budaya yang mereka banggakan kepada parapengunjung. Hal ini juga dapat meningkatkan pengalaman para wisatawan ditempat wisata mereka.

Permasalahan yang terjadi belum tersedia hiasan dinding yang khas pada rumah wisata, belum diterapkannya layanan tata graha yang baik bagi tamu di rumah wisata, dan minimnya pengetahuan tentang pentingnyahygiene dan sanitasi rumah wisata serta rendahnyapengetahuan dan ketrampilan penataan kamar rumah wisata. Adapun solusi yang ditawarkan mengatasi permasalahan tersebut dilakukannya kegiatan pengabdian masyarakat dengan memberikan pelatihan berupapembuatan hiasan dinding yang khas, tatagraha, tentang hygiene dan sanitasi dan tetang penataan kamar.Oleh karena itu dilakukan kegiatan pengabdian berupa Pelatihan Tata Graha Rumah Wisata Bagi Pengelola Homestay di Nagari Harau.

\section{METODE}

Kegiatan pengabdian yang dilakukan berupa pelatihan tata graha rumah wisata. Khalayak sasaran kegiatan pengabdian adalah para pengelola homestay di Nagari Harau Kecamatan Harau Kabupaten Limapuluh Kota. 
Supaya tujuan dapat tercapai secara maksimal, maka dalam pelaksanaan pengabdian bagi masyarakat digunakan metode yaitu:

1. Metode ceramah dan tanya jawab

Metode ini digunakan untuk menjelaskan pengetahuan dan meningkatkan kelestarian rumah wisata di tengah-tengah masyarakat. Dalam ceramah, akan disampaikan beberapa materi yaitu:

a. Tata Graha dalam pelayanan dan informasi pariwisata, kegiatannya meliputi pembersihan, perawatan, pemeliharaan, dan penataan kamar dan kamar mandi, serta secara umum seluruh bagian rumah wisata baik interior maupun eksterior.

b. Bagaimana proses perawatan berkala sehingga prasarana yang ada menjadi bermanfaat jangka panjang.

2. Metode pelatihan keterampilan

Metode ini digunakan untuk memberikan keterampilan membersihkan, merawat, mendesain, menata dan membuat hiasan pada rumah wisata guna meningkatkan kelestarian rumah wisata. Pelatihan keterampilan yang diberikan yaitu: desain dan pembuatan hiasan dinding, perawatan dan pemeliharaan kamar dan kamar mandi, penataan tempat tidur dan kamar mandi pada rumah wisata.Final produk dalam penelitian ini yaitu desain final kedua yang merupakan revisi dari hasil validasi. Adapun desain yang dihasilkan sebagai Simbol, Peta, dan Signage.

\section{HASIL DAN PEMBAHASAN}

Kegiatan pengabdian dilakukan olehtimDosen yang berasal dari Program Studi Manajemen Fakultas Pariwisata dan Perhotelan UNP dandari Program Studi Pendidikan Teknik Elektronika Fakultas Teknik UNP.Kegiatan pengabdian bertema pelatihan tata graha rumah wisata bagi pengelola homestay.Kegiatan pengabdianinidilaksanakan di Kenagarian Harau, Kecamatan Harau, Kabupaten Limapuluh Kota.

Tata graha menurut (Dimyati, 2002), merupakan bagian yang bertugas memelihara kebersihan, kerapian, dan kelengkapan kamar-kamar tamu, restoran, 
bar, dan tempat-tempat umum dalam hotel, termasuk tempat untuk karyawan, kecuali tempat yang menjadi tanggung jawab standar misalnya kitchen area. Tidak jauh berbeda, (Nawar, 2002) mendefinisikan tata graha adalah bagian departemen yang mengatur atau menata peralatan, menjaga kebersihan, memperbaiki kerusakan, dan memberi dekorasi dengan tujuan agar rumah (hotel) tampak rapi, bersih, menarik, dan menyenangkan bagi penghuni atau tamu yang menginap.

Senada dengan hal itu, (Rumekso, 2002) menyatakan bahwa tata graha merupakan bagian yang bertugas dan bertanggung jawab untuk menjaga kebersihan, kerapian, keindahan, dan kenyamanan di seluruh area hotel, baik di luar gedung maupun di dalam gedung, termasuk kamar-kamar tamu, ruanganruangan yang disewa oleh para tamu, restaurant, office, serta toilet. Berdasarkan beberapa definisi di atas, maka dapat ditarik kesimpulan bahwa tata graha merupakan bagian yang berfungsi untuk menjaga kebersihan, kerapian, kenyamanan serta keindahan pada sebuah layanan penginapan baik di luar maupun di dalam gedung.

Kegiatan pengabdiandimulai dari tahap persiapan terlebih dahuluyaituobservasi lapangan untuk memperoleh data awal tentang permasalahan yang dihadapi pihak pengelola homestay, melakukan analisis kebutuhan dan menawarkan solusi penyelesaian. Kemudian sosialiasi untuk melakukan koordinasi dengan pihakpengelola homestay.Kegiatan dilakukan untukmembahas tentang rencana umum dan teknis (waktu dan tempat pelaksanaan kegiatan, peserta yang mengikuti kegiatan pengabdian serta perangkatapa saja yang dibutuhkan). Mempersiapkan bahan materi dan peralatan terkaitpelatihantata graha,seperti modul pelatihan, serifikat, dan nama-nama pengelola homestay yang ikut serta dan mempersiapkan konsumsi untuk peserta dan tim pengabdian.

Pada tahap pelaksanaan kegiatan pengabdian, penyaji menyampaikan materi tentang tata graha dengan cara mendemonstrasikan langkah demi langkah. 


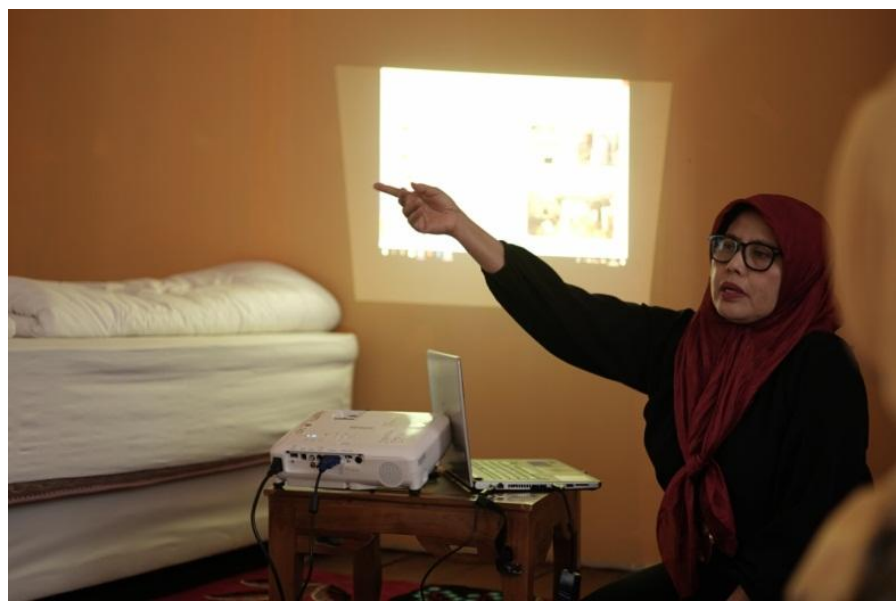

Gambar 1. Penyampaian Materi Pelatihan

Pokok bahasan yang disampaikan yaknidimulai dengan pengenalan Homestay dankemudian dilanjutkan dengan materi Operasional Tata Graha yang meliputi Homestay, Cleaning Equipment, BathroomCleaning,,Room Cleaning. Setelah penyajian materi dengan slide presentasi dan menayangkan video, kemudian dilanjutkan dengan demonstrasi Make up Room dan Making bedoleh pemateri yang didampingi oleh mahasiswa.

Penyampaian materi ini diharapkan dapat menjadi pengetahuan dasar bagi pemilik dan pengelola homestayuntuk dapat menyediakan layanan homestay yang sesuai dengan standar akomodasi dan pelayanan. Sebagaimana metode yang dipilih dalam kegiatan ini yakni metode ceramah dan tanya jawab, maka setelah narasumber memaparkan materi maka diberikan kesempatan kepada peserta untuk berinterkasi langsung dengan narasumber untuk menanyakan hal yang belum mereka pahami. Hal ini berarti bahwa antusisme peserta cukup tinggi untuk menggali pengetahuan langsung kepada narasumber.

Materi berikutnya dilanjutkan dengan praktek Making bedlangsung oleh peserta pelatihan dengan pendampingan dari tim pengabdian baik dari dosen maupun mahasiswa. Apabila peserta pelatihan mengalami kesulitan maka tim pengabdian dapat membantu dan mengarahkan untuk membimbing peserta.Tujuan diberikan pendampingan agar pelatihan berjalan lebih efektif dan efisien serta memudahkan peserta dalam memahami materi pelatihan. 


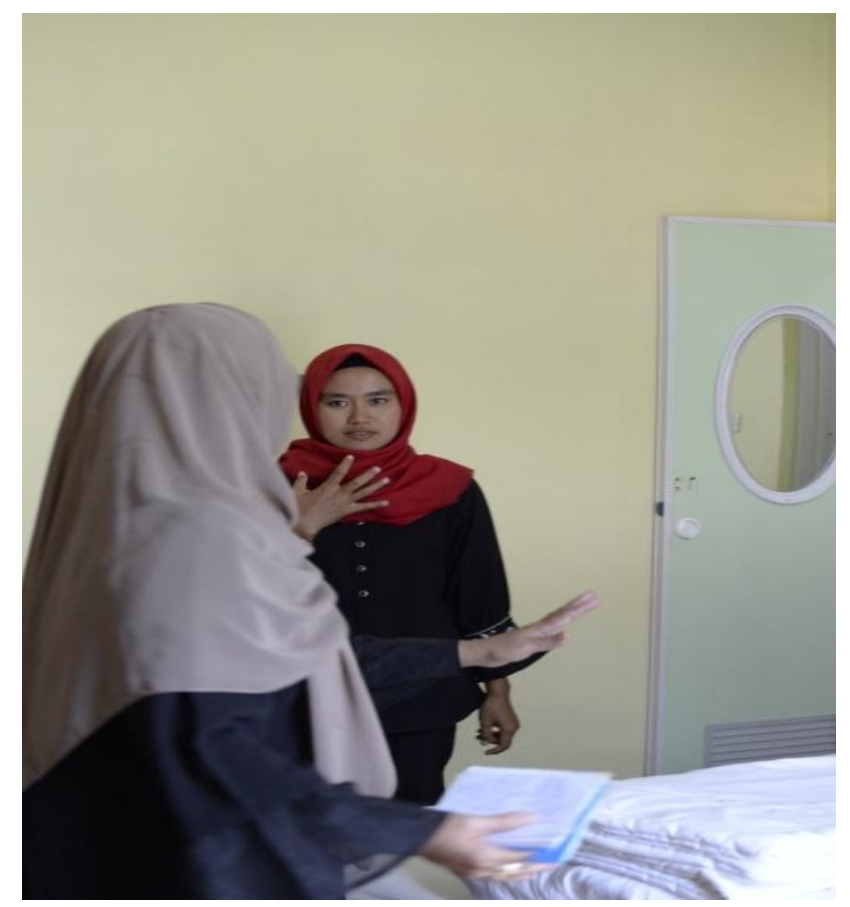

Gambar 2. Pendampingan Pelatihan

Setelah mendemonstrasikan making bed, maka selanjutnya pesertamempraktikan secara langsung.

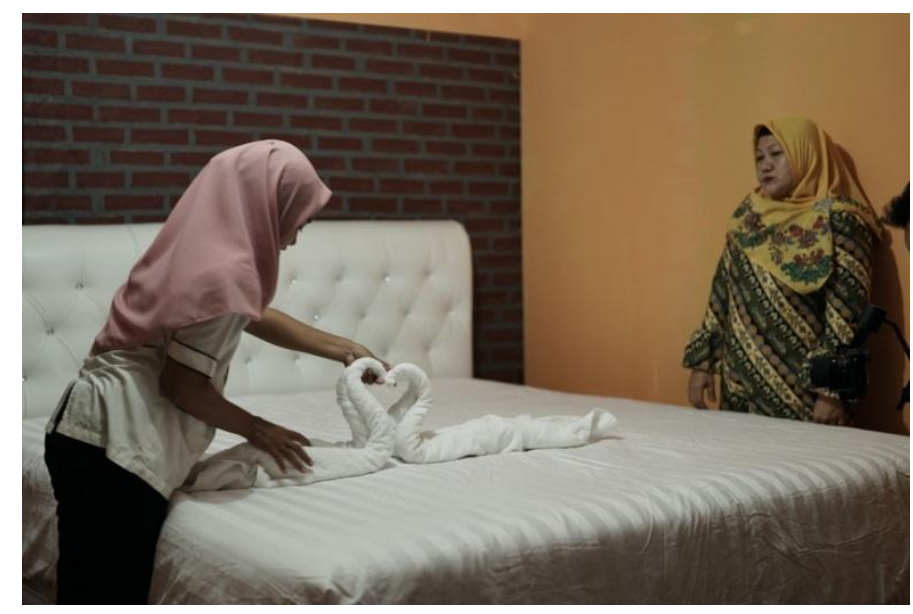

Gambar 3. Peserta melakukan praktek making bed

Dengan dilaksanakannya kegiatan pengabdian, para pengelola homestaysedikit demi sedikit mulai memahami bagaimana caramelakukan tata graha Rumah Wisata. Hal ini diharapkan dapat menjadi bekal bagi pemilik dan pengelola homestay agar menjadi lebih baik dan menarik khususnya bagi wisatawan. 


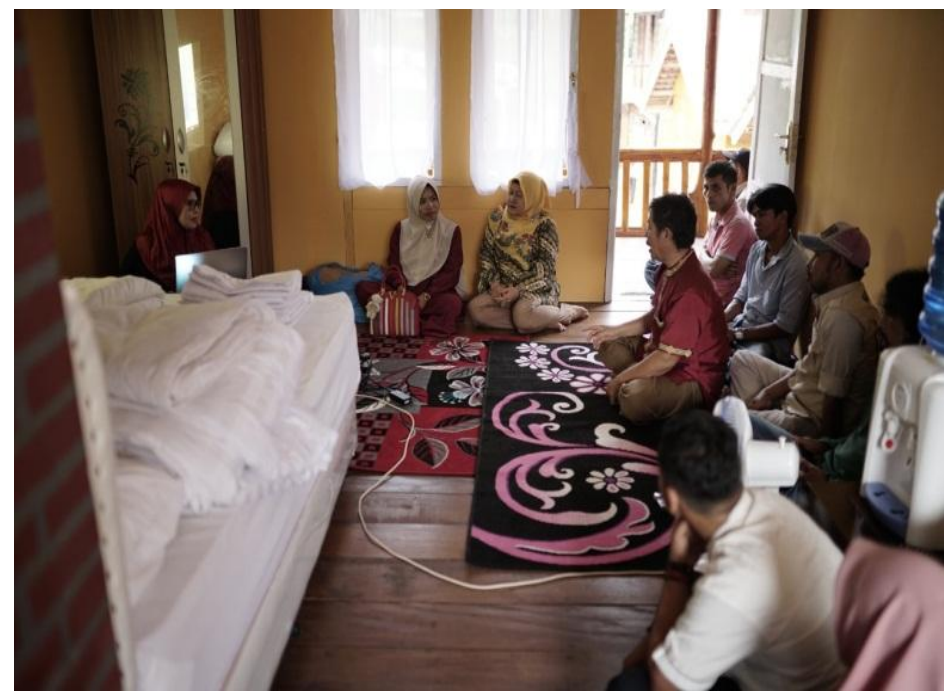

Gambar 4. Suasana Pelatihan Tata Graha

Pada tahap akhir dari hasil kegiatan pengabdian tersebut, tim dosen juga melakukan refleksi dan evaluasi guna memperbaiki kelemahan yang terjadi selama pelatihan berlangsung dan menjadikan bahan pertimbangan untuk melakukan kegiatan pengabdian selanjutnya.Adapun hambatan-hambatan dan kelemahan yang ditemukan dalam pelaksanaan pengabdian di Nagari Harau Kecamatan Harau Kabupaten Limapuluh Kota adalah: (1) pengelolahomestay masih pemula sehingga belum memahami konsep dari sebuah homestay; dan (2)Homestay yang tidak sesuai kriteria untuk tempat penginapan karena fasilitas yang masih kurang sehingga sulit memberikan contoh yang ideal;(3) ruangkamar yang sempit sehingga tidak leluasa ketika melatih peserta tentang make up room dan making bed.

Berdasarkan kelemahan yang ditemukan, maka tim pengabdian melakukan refleksi dan evaluasi dengan caramemberikan pelatihan,demonstrasi step by step sehingga pengelolahomestay memahami materi, tim pengabdian menayangkan video sehingga peserta pengabdian jadi lebih paham meski fasilitasnya kurang. Dengan keterbatasan ruangan yang sempit maka peserta saat prakteknya hanya diujicobakan beberapa orang peserta saja.

Secara umum kegiatan pengabdian yang dilaksanakan tim dosen berjalan lancar dan berdasarkan respon yang dihasilkan dari wawancara kepada para pengelola homestay yang mengikuti kegiatan pengabdian tergolong baik, para 
peserta sangat antusias, aktif, dan termotivasi terhadap kegiatan pengabdian tersebut, serta sangat membantu peserta dalam menunjang proses operasional tata graha di homestay mereka. Berdasarkan dari sisi materi pelatihan yang diberikan dalam kegiatan pengabdian banyak mendapatkan pengetahuan, meningkatkan kompetensi, dan pengalaman baru bagi peserta.

Sedangkan bagi tim dosen memperoleh masukan yang bermanfaat dan dapat turut andil dalam mengatasi permasalahan para pengelola homestay, terkait operasional tata graha. Kegiatan pengadian juga dapat menambah pengalaman bermitra dan berkerja sama dengan pengelola homestay di Nagari Harau Kecamatan Harau Kabupaten Limapuluh Kota.

\section{SIMPULAN}

Berdasarkan hasil dari kegiatan pengabdiandi Nagari Harau Kecamatan Harau Kabupaten Limapuluh Kota berupa pelatihan tata graha rumah wisata bagi pengelola homestay, diperoleh hasil sebagai berikut: (1) Pelaksanaan kegiatan terselenggara dengan baik, berjalan lancar, dan peserta memiliki antusiasyang luar biasa sepanjang kegiatan berlangsung; (2) Peserta sangat aktif dalam mempraktikan operasional tata graha dan mengikuti dengan motivasi yang tinggi, dan (3) Peserta pelatihan mendapatkan keterampilan baru dalamoperasional tata graha, sehingga dapat diimplementasikan di homestay yang mereka kelola sehingga dapat meningkatkan kualitas homestay.Berdasarkan evaluasi dari pelaksanaan kegiatan pengadiandi Nagari Harau Kecamatan Harau Kabupaten Limapuluh Kota,maka disarankan: (1) Rekomendasi perbaikan untuk kegiatan pengabdian berikutnya agar dapat memberikan pelatihan yang lebih luas dengan penambahan waktu yang lebih lama dan dapat melibatkan para pengelola homestaydi Kabupaten Limapuluh Kota; (2) Untuk kegiatan pengabdian berikutnya diharapkan dapat memberikan pelatihan dalam operasional secara rutin untuk mengupdate pengetahuan pengelola homestay; dan (3) Menambahkan materi kegiatan pengabdian untuk pengelola homestay seperti pengetahuan tata boga. 


\section{UCAPAN TERIMA KASIH}

Terima kasih diucapkan kepada pihak mitra pengabdian kepada masyarakat yaknipengelola homestay di Nagari Harau Kecamatan Harau Kabupaten Limapuluh Kota. Serta pihak Universitas Negeri Padang yang telah mendukung memberikan bantuan dana untuk kelancaran kegiatan pengabdian kepada masyarakat.

\section{DAFTAR PUSTAKA}

Dimyati. (2002). Belajar Pembelajaran. Jakarta: Rineka Cipta.

Mandal, P. and Vong, J., 2015. Development of Tourism and the Hospitality Industry in Southeast Asia. Singapore: Springer.

Nawar, A. (2002). Psikologi Pelayanan. Bandung: Alfabeta.

Rumekso, S. (2002). House Keeping Hotel. Yogyakarta: Andi.

Suwantoro, G. (1997). Dasar-dasar Pariwisata. Yogyakarta: Andi.

Utama, I., Rai, G.B. and Mahadewi, N.M.E., 2012. Metodologi Penelitian Pariwisata dan Perhotelan. Yogyakarta: ANDI.

\section{Panduan Praktik Homestay yang baik. ILO ASEAN.}

